\title{
Simulations And Injection Molding Experiments For Aluminum Nitride Feedstock
}

\author{
Kunal H. Kate ${ }^{1}$, Ravi K. Enneti ${ }^{2}$, Tim McCabe ${ }^{3}$ and Sundar V. Atre ${ }^{1^{*}}$ \\ 1 University of Louisville \\ Louisville, KY 40292 \\ ${ }^{2}$ Global Tungsten and Powders Corporation \\ Towanda, PA 18848 \\ ${ }^{3}$ Kinetics, A Dynacast Company \\ Wilsonville, OR
}

*To whom correspondence should be addressed: sundar.atre@louisville.edu, phone: 541-9081483

\begin{abstract}
Powder injection molding (PIM) simulations are useful for predicting mold-filling behavior because they aid in material, process and part design. To perform PIM simulations, measurements for feedstock properties such as physical, thermal, and rheological are required as input parameters. The availability of data for such feedstock properties is limited and fresh measurements are often required in order to perform PIM simulations for variations in feedstock composition. A recent study by our group presented a procedure to estimate feedstock properties and use them in mold-filling simulations. The present work compares the predictions of PIM mold-filling simulations using experimental and estimated feedstock properties with injection-molding experiments. Aluminum nitride (AIN) feedstock of 80.5 wt.\% was compounded using a twin-screw extruder and injection-molded as tensile bars. Injection-molding experiments were performed using the AIN feedstock at various melt temperatures and injection pressures to obtain complete and partially filled parts. Simulations were performed using measured and estimated AIN feedstock properties on the tensile-bar geometry used during injection molding experiments. Melt temperature was varied while performing simulations to obtain a process window for complete and partially filled parts.
\end{abstract}


A comparison between injection molding experiments and simulations was made to understand the dependence of the estimated and experimental feedstock properties in predicting mold filling behavior.

\section{Introduction}

Powder injection molding (PIM) is a multi-step process that can be divided into four basic steps: 1) ceramic or metal powders are mixed with polymer binders to form a homogenous feedstock using a twin-screw extruder, 2) the feedstock is injection molded into desired geometries using an injection molding machine, 3) the binder phase is debound from the molded parts by thermal or solvent based techniques, and 4) debound parts are sintered to achieve final parts. The PIM simulations are generally performed typically after feedstock compounding to identify appropriate process and geometry attributes for optimum molding [1]-[12]. Common injection molding simulation tools include Autodesk Moldflow, Sigmasoft, PIMsolver, and Modlex3D.

To perform PIM simulations, feedstock property measurements for density, thermal conductivity, and specific heat are required for a range of temperatures. Further, viscosity measurements are required for a range of shear rates and temperatures, and specific volume measurements are required for a range of temperatures and pressures [1-4]. Availability of such feedstock property data is limited and properties are typically measured for a particular composition.

A recent work by our group suggests a design method that uses empirical equations and estimate feedstock properties as a function of composition, filler properties, and binder properties [17]. This design method employs the use of available literature filler and binder properties to estimate physical, thermal and rheological properties for nine different ceramic feedstocks [17]. An extension of this work outlines a procedure to use feedstock property estimates in mold-filling simulations [18].

In the current work, 80.5-weight percent aluminum nitride (AIN) feedstock was extruded and injection molded into a tensile bar geometry. Injection molding was performed as a function of melt temperature and injection pressure in order to obtain parts with partial 
and complete mold filling. Feedstock properties for AIN were measured at Datapoint Labs and estimated using our design procedure for PIM simulations [5, 6]. To perform PIM simulations a tensile bar geometry was designed according to the mold tool dimensions. Simulations were performed using measured and estimated AIN feedstock properties at various melt temperatures and injection pressures to obtain complete and partially filled parts. Comparisons of melt temperatures from simulation and experiments were made to understand the effectiveness of PIM simulations in predicting mold-filling behavior.

\section{Experimental Methods}

Commercially available aluminum nitride (AIN) powder (median particle size of $1 \mu \mathrm{m}$ ) and a wax-polymer binder were used as starting materials. The binder is composed of paraffin wax, low-density polyethylene, polypropylene, and stearic acid. Details of the binder composition and feedstock compounding are provided [19], [20]. A feedstock with 80.5 wt. \% AIN powder was compounded using a $27 \mathrm{~mm}$ twin-screw extruder with a length to diameter (L/D) ratio of 40 .

Material property measurements were made at Datapoint Labs (Ithaca, NY) for the AIN feedstock and a wax-polymer binder [7, 8]. Solid density measurements were made for AIN feedstock and wax-polymer binder using Archimedes principle as laid out in ASTM standard D792. The melt density measurement was done using a Gottfert Rheograph capillary rheometer in accordance with ASTM D3835 for AIN feedstock and a waxpolymer binder. A Perkin Elmer differential scanning calorimetry (DSC) was used to measure specific heats for AIN feedstock and a wax-polymer binder in accordance with ASTM E1269 standard. Thermal conductivity measurements for AIN feedstock and the wax-polymer binder were made using a K-System II thermal conductivity system in accordance with ASTM standard D5930. Viscosity for AIN feedstock and the waxpolymer binder was measured according to ASTM D3835 using a Gottfert Rheograph capillary rheometer. Pressure-volume-temperature (PVT) measurements for AIN feedstock and the wax-polymer binder were made with a Gnomix PVT apparatus in accordance with ASTM D792 [7, 8]. The feedstock property measurements were 
compared to values estimated using models listed in Table 1. Description of the symbols used in Table 1 and throughout this paper is presented in Table 2.

The AIN feedstock was injection molded into a tensile bar geometry using an Arburg $221 \mathrm{M}$ injection-molding machine. An injection gate with a size of $6.5 \mathrm{~mm}$ was used to inject the AIN feedstock into the mold cavity. Injection molding experiments were performed at a set of melt temperatures and injection pressures to obtain parts with complete and incomplete mold fill (Table 3). In the first molding experiment (Table 3) the injection pressure $\left(\mathrm{P}_{\mathrm{i}}\right)$ was set at $38 \mathrm{MPa}$ and melt temperature $\left(\mathrm{T}_{\mathrm{m}}\right)$ was set at 455 K. A total of 50 parts with no defects were molded during this experiment and a specimen part is shown in Figure 1a. To understand the effect of decreases in injection pressure and melt temperature on the molding behavior, experiments \# 2-4 were performed (Table 3). For Experiments 2-4 the melt temperatures was decreased from $444 \mathrm{~K}$ to $422 \mathrm{~K}$ while keeping injection pressure constant at $14 \mathrm{MPa}$ to obtain parts with incomplete mold fill (short shot). A total of four to five specimens were injection molded in each of the experiments 2-4 and sample molded specimens are presented in Figure 1b-d. All injection molding experiments listed in Table 3 were performed at injection speed of $33 \mathrm{~cm}^{3} / \mathrm{s}$, the initial packing pressure was set at $100 \%$ of the injection pressure value for the first second and then it was reduced to $65 \%$ of the injection pressure value for the next $1.2 \mathrm{~s}$. To calculate the percentage of part filled of the incompletely filled samples, their weights were compared to those of the filled samples.

To perform mold-filling simulations, the tensile bar geometry model was imported into the Autodesk Moldflow software. The tensile bar geometry was meshed using an automated solid 3D meshing protocol based on finite element analysis. A gate size of $6.5 \mathrm{~mm}$ was set to perform molding simulations. A fill-and-pack type process module was selected to perform simulations. Simulations were performed using measured and estimated AIN feedstock property values.

Simulations were performed on a 3D tensile bar geometry model designed using Solidworks in accordance with the mold tool dimensions. The dimensions for the tensile bar geometry are shown in Figure 2. Initial simulations were performed using Autodesk Moldflow software for injection molding conditions listed in Table 3. Additional 
simulations for lower values of melt temperature were performed in case short shots were not obtained at the melt temperature of $422 \mathrm{~K}$.

\section{Results and Discussion}

\subsection{Properties}

The physical, thermal and rheological properties of AIN feedstock were estimated using selected empirical models presented in Table 1. The empirical models estimate material properties of feedstocks as a function of feedstock composition and filler and binder properties. The empirical models were selected by performing an in-depth statistical analysis on various published models that were fitted to literature data on experimentally-measured properties of powder-polymer mixtures [13]. The thermal, physical and rheological properties of the wax-polymer binder and thermal and physical properties of AIN filler were collected from literature. Filler properties collected from literature were reported for $300 \mathrm{~K}$.

The solid and melt density of AIN feedstock was estimated using Equation 1 for 22 data points of AIN filler density $\left(3300 \pm 50 \mathrm{~kg} / \mathrm{m}^{3}\right)$ [13-27]. Estimations were made for the wax-polymer solid and melt density values of 870 and $700 \mathrm{~kg} / \mathrm{m}^{3}$ respectively and details for estimation procedure are reported elsewhere [17-19, 33]. The experimentally measured and estimated values of solid and melt densities for the AIN feedstock are presented in Table 4. The average values of density estimates and measured values of density from Table 4 were used to create a dataset necessary for performing moldfilling simulations.

Furthermore, the densities values of AIN filler and the wax-polymer binder in conjunction with Equation 2 and $\mathbf{3}$ were used to calculate volume fraction of the AIN feedstock. Volume fraction values are required to estimate feedstock properties such as viscosity and thermal conductivity.

The specific heat of the AIN feedstock was estimated using Equation 4 as a function of temperature for six data points of filler specific heats $(800 \pm 30 \mathrm{~J} / \mathrm{kg} . \mathrm{K})$ [34-36]. Estimations were made for the wax-polymer binder specific heats reported for temperatures between 283 and $430 \mathrm{~K}$. The specific heat values of the wax-polymer 
binder used for this estimation ranged between 2080 and $4640 \mathrm{~J} / \mathrm{kg} . \mathrm{K}$ and details for the estimation procedure are reported elsewhere [17-19, 33]. The experimentally measured and estimated values of specific heats for the AIN feedstock are presented in Table 5. The average values of specific heat estimates and measured values of specific heats from Table 5 were used to create a dataset necessary for performing mold-filling simulations.

The thermal conductivity of the AIN feedstock was estimated using Equation 5 as a function of temperature for the 18 data points of filler specific heats $(230 \pm 70 \mathrm{~W} / \mathrm{m} . \mathrm{K})$ [21], [24], [26], [30]-[32], [37]-[40] Estimations were made for the wax-polymer binder thermal conductivity reported for temperature between 310 and $440 \mathrm{~K}$. The thermal conductivity values of the wax-polymer binder used for this estimation ranged between 0.162 and $0.195 \mathrm{~W} / \mathrm{m} . \mathrm{K}$ and details for the estimation procedure are reported elsewhere $[17-19,33]$. The experimentally measured and estimated values of thermal conductivity for the AIN feedstock are presented in Table 6. The average values of thermal conductivity estimates and measured values of thermal conductivity from Table 6 were used to create a dataset necessary for performing mold-filling simulations.

In the present study, a simplified Krieger-Dougherty model (Equation 6) was used to estimate viscosity. The viscosity of the AIN feedstock was estimated for 40 different shear rates in ranges between 10 and $10^{4} \mathrm{~s}^{-1}$ and for temperatures of 415, 420, 425 and $430 \mathrm{~K}$ using Equation 6 and polymer binder viscosity $\left(\eta_{b \text { exp }}\right)$ values from Figure 3. The viscosity data for the wax-polymer binder was gathered from literature [19]. The volume fraction of the AIN feedstock $\left(\phi_{p}\right)$ was calculated to be 0.52 using Equation 2. Viscosity was estimated for a $\phi_{\max }$ of 0.64 critical filler content and details for the estimation procedure are reported elsewhere [17-19, 33]. The representative values for the estimated and experimental AIN feedstock viscosities are shown in Table 7.

To perform mold-filling simulations the viscosity of the AIN feedstock has to be represented in terms of fitted constants. The Cross-WLF model (Equations 7 and 8) was used to extract fitted constants from the measured and estimated AIN feedstock viscosity (Table 8) and details for the extraction procedure are reported elsewhere [17- 
19, 33]. The Cross-WLF constants from Table 8 were further used to create a dataset necessary for performing mold filling simulations.

A rule-of-mixtures model (Equation 9) was used to estimate the specific volume of AIN feedstock. To calculate the specific volume of AIN filler, the reciprocals of the densities of the AIN filler were used. The specific volume of the AIN feedstock was estimated for 20 different temperatures in ranges between 300 and $453 \mathrm{~K}$ and for pressures of 0,50 ,

100, 150, and $200 \mathrm{MPa}$ using Equation 9 and polymer binder specific volume $\left(v_{b \text { exp }}\right)$ values from Figure 4. The specific volume data for the wax-polymer binder was gathered from literature [19]. The average value for the AIN filler specific volume was used to estimate the AIN feedstock specific volume and details for the estimation procedure are reported elsewhere $[17-19,33]$. The representative values for the estimated and experimental AIN feedstock specific volumes are shown in Table 9.

To perform mold-filling simulations, the specific volume of the AIN feedstock needs to be represented in terms of fitted constants. A dual-domain Tait model (Equations 1013) was used to extract these fitted constants for the estimated and measured AIN feedstock specific volumes (Table 10) and details for the extraction procedure are reported elsewhere [17-19, 33]. The Dual-domain Tait constants from Table 10 were further used to create a dataset necessary for performing mold filling simulations.

\subsection{Injection molding results}

The first injection molding experiment listed in Table 1 was performed for an injection pressure of $38 \mathrm{MPa}$ and a melt temperature of $455 \mathrm{~K}$ with the AIN feedstock. This particular combination of injection pressure and melt temperature resulted in $100 \%$ filled parts (Figure 1a). Additional injection molding experiments with an increase in injection pressure to a value of $48 \mathrm{MPa}$ also resulted in a $100 \%$ filled parts. This behavior indicated that an increase in injection pressure from 30 to $48 \mathrm{MPa}$ showed no sensitivity towards the fraction of mold cavity that was filled with feedstock.

Injection molding experiments 2-4 listed in Table 1 were performed at a lower injection pressure of $14 \mathrm{MPa}$ and the melt temperature was decreased from $444 \mathrm{~K}$ to $389 \mathrm{~K}$. 
Experiments \# 2-4 were performed to investigate the sensitivity of variation in injection pressure and melt temperature towards part filling. Specimen images of molded parts for experiments \# 2-4 are represented in Figure 1b-d. Molding experiment \#2 performed at a melt temperature of $444 \mathrm{~K}$ resulted in a $100 \%$ filled part (Figure $1 \mathrm{~b}$ ). Molding experiment \# 3 performed at a melt temperature of $433 \mathrm{~K}$ resulted in a $89 \%$ filled part (Figure 1c). Molding experiment \#3 performed at a melt temperature of $389 \mathrm{~K}$ resulted in $71 \%$ filled part (Figure 1d). Thus, the onset of an incomplete mold filling (short shot) was experimentally estimated at a melt temperature of $433 \mathrm{~K}$ (Figure 1c).

The PIM simulations were performed using the AIN feedstock property datasets 1-3 presented in Table 11. Feedstock property dataset 1 comprises of experimentally measured physical, thermal and rheological feedstock properties. Feedstock property dataset 2 comprises of estimated physical, thermal and rheological properties. Feedstock property dataset 3 comprises of estimated physical, thermal properties, and experimentally measured rheological properties.

In order to study the effectiveness of the PIM simulations in predicting mold-filling behavior, simulations were performed for the experimental processing conditions listed in Table 1. Figure 5 show a typical progressive mold-filling behavior for a PIM simulation performed at an injection pressure of $38 \mathrm{MPa}$ and melt temperature of $455 \mathrm{~K}$ using feedstock property dataset 1 . A similar progressive mold-filling behavior was observed for simulations performed with feedstock property datasets 2 and 3 at an injection pressure of $38 \mathrm{MPa}$.

Simulations performed at a lower injection pressure of $14 \mathrm{MPa}$ and melt temperature of 444K using datasets 1-3 also displayed a filling profile similar to that observed in Figure 5. In order to study, how well PIM simulations predict the melt temperature at which the short shot occurs, the melt temperature was lowered in simulations until a short shot occurred. The simulation performed with dataset 1 resulted in complete mold fill for melt temperatures until $350 \mathrm{~K}$ and a short shot occurred at a melt temperature of $330 \mathrm{~K}$ with 89 percent mold fill (Figure 6a). Simulations with dataset 2 resulted in complete mold fill for melt temperatures until $430 \mathrm{~K}$ and a short shot occurred at a melt temperature of $420 \mathrm{~K}$ with 97 percent mold fill (Figure 6b). Simulations with feedstock property dataset 
3 resulted in complete mold fill for melt temperatures until $353 \mathrm{~K}$ and a short shot occurred at a melt temperature of $333 \mathrm{~K}$ with 84 percent mold fill (Figure $6 \mathrm{c}$ ).

A plot of percent mold fill with melt temperature for injection molding experiments and simulations is presented in Figure 7. Simulation results with feedstock property datasets 1-3 predict a complete mold fill for process input conditions set according to molding experiments \#1 and \#2 (Table 1). This behavior was also observed for the injection molding experiments. However, as the melt temperature values were lowered, the results of the onset of short shots from simulations differed from molding experiment observations.

A plot of part weight with melt temperature for injection molding experiments and simulations are presented in Figure 8. Part weights for injection molding experiments with complete mold fill were typically around $\sim 9.95 \mathrm{~g}$ and had a standard deviation of \pm 0.02 . Simulations with feedstock property datasets $1-3$ predict part weights with comparable accuracy for process input conditions set according to molding experiments \#1 and \#2 (Table 1). Simulations with feedstock property dataset 3 for a melt temperature of $450 \mathrm{~K}$ showed the highest deviation of $8 \%$ in predicted part weight. However, as the melt temperature values were lowered to $389 \mathrm{~K}$ the deviation of part weight predictions from the molding experiments increased by $31 \%$ for simulations using feedstock property dataset 2 .

A plot of percent-linear shrinkage with melt temperature for injection molding experiments and simulations is presented in Figure 9. Percent linear shrinkages for injection molding experiments with complete mold fill were typically around $0.8 \%$ and had a standard deviation of \pm 0.15 . Simulations with feedstock property datasets $1-3$ predict percent linear shrinkages with comparable accuracy for process input conditions set according to molding experiments \#1 and \#2 (Table 1). For ceramic-filled polymers, the percent linear shrinkage has been reported to range between 0.4 and $0.8 \%$ [41]. The predicted and experimental values of percent-linear shrinkage are on the same order of magnitude as observed in the limited data in the literature for ceramic feedstocks. 
A plot of injection pressure and melt temperature for injection molding experiments and simulations are presented in Figure 10. The injection-molding experiments were conducted by setting an injection pressure to a desired value. The feedstock melt was injected at this pressure and a set flow rate of $33 \mathrm{~cm} / \mathrm{s}$. The PIM simulations also allow setting of a specific value for injection pressure and flow rate. The simulation tries to attain this injection pressure value by filling the mold cavity at the desired flow rate.

Figure 10 shows the simulated values for the maximum injection pressure that can be attained during mold filling. It can be observed from Figure $\mathbf{1 0}$ that simulations with feedstock property datasets 1-3 underestimate injection pressures by a factor of 30 and 10 for process input conditions set according to molding experiments \#1 and \#2 respectively. (Table 2). For simulations performed with feedstock property dataset 2 and for process input conditions set according to molding experiments \#3 and \#4 (Table 2), the injection pressure values are close to that of the actual experiments. A cause for this sensitivity is not presently understood. In the future, simulations using a different PIM simulation software package based on alternative constitutive models will be studied.

\section{Conclusions}

The present study can be used as a design approach to perform PIM simulations by estimating feedstock properties and study a wide variety of material systems The current investigation was found to have the following key attributes:

1. Literature filler properties can be used in conjunction with mixture models to estimate physical, thermal, and rheological properties of AIN feedstocks.

2. Mold-filling behavior for injection molding experiments and PIM simulations are similar for parts that showed $100 \%$ mold filling. Short shot predictions using simulations were however not in full agreement with injection-molding experiments.

3. Part weight predictions by PIM simulations melt temperature $444-455 \mathrm{~K}$ and injection pressures of 14-38 $\mathrm{MPa}$, were in agreement with molding experiments within a maximum error of $8 \%$. 
4. Percent linear shrinkages for PIM simulations ranged between $0.3-1.4 \%$ and were comparable to results from injection molding experiments that ranged between 0.65 $0.95 \%$.

5. Injection pressure predictions by simulations are very sensitive to feedstock properties and warrant further investigation using other PIM software packages.

\section{Acknowledgements}

The authors thank the financial support obtained from the National Science Foundation (CMMI 1200144). 


\section{References}

[1] R. Urval, S. Lee, S. V. Atre, S.-J. Park, and R. M. German, "Optimisation of process conditions in powder injection moulding of microsystem components using a robust design method: part I. primary design parameters," Powder Metall., vol. 51, no. 2, pp. 133-142, Jun. 2008.

[2] R. Urval, S. Lee, S. V. Atre, S.-J. Park, and R. M. German, "Optimisation of process conditions in powder injection moulding of microsystem components using robust design method Part 2 - Secondary design parameters," Powder Metall., vol. 53, no. 1, pp. 71-81, Mar. 2010.

[3] J. Kim, S. Ahn, S. V. Atre, S. J. Park, T. G. Kang, and R. M. German, "Imbalance filling of multi-cavity tooling during powder injection molding," Powder Technol., vol. 257, pp. 124-131, May 2014.

[4] R. K. Enneti, S. J. Park, J. Palagi de Souza, and S. V. Atre, "Critical Issues In Manufacturing Dental Brackets By Powder Injection Molding," Int. J. Powder Metall., vol. 48, no. 2, pp. 23-39, 2012.

[5] S. Laddha, C. Wu, G. K. lingam, K. Simmons, S. vallury, S. Lee, S. J. Park, R. M. German, P. Vilma, A. Varez, and S. V. Atre, "Characterization of Alumina Feedstock with Polyacetal and Wax-Polymer Binder Systems for Micro Powder Injection Moulding," PIM International, vol. 3, no. 3, pp. 64-70, 2009.

[6] S. J. Park, S. Y. Ahn, T. G. Kang, S. T. Chung, Y. S. Kwon, S. Chung, S. G. Kim, S. Kim, S. V. Atre, S. Lee, and R. M. German, "Computer Simulations in Powder Injection Molding," Int. J. Powder Metall., vol. 46, no. 3, pp. 37-46, 2010.

[7] R. Urval, C. Wu, S. V. Atre, S. J. Park, and R. M. German, "CAE-Based Process Design for Microfluidic Components," Powder Injection Molding Internationa," PIM International, no. I, pp. 48-54, 2007.

[8] S. Laddha, C. Wu, S. J. Park, S. Lee, S. Ahn, R. M. German, and S. V. Atre, "Analysis of Macroscale Mold Filling Defects in Micro Powder Injection Molding," Int. J. Powder Metall., vol. 46, no. 3, pp. 49-59, 2010.

[9] S. V. Atre, S.-J. Park, R. Zauner, and R. M. German, "Process simulation of powder injection moulding: identification of significant parameters during mould filling phase," Powder Metall., vol. 50, no. 1, pp. 76-85, Mar. 2007. 
[10] S. Ahn, S. T. Chung, S. V. Atre, S. J. Park, and R. M. German, "Integrated filling, packing and cooling CAE analysis of powder injection moulding parts," Powder Metall., vol. 51, no. 4, pp. 318-326, Dec. 2008.

[11] S. W. Lee, S. Ahn, C. J. Whang, S. J. Park, S. V. Atre, J. Kim, and R. M. German, "Effects of process parameters in plastic, metal, and ceramic injection molding processes," Korea-Aust. Rheol. J., vol. 23, no. 3, pp. 127-138, Sep. 2011.

[12] S. Ahn, S. J. Park, S. Lee, S. V. Atre, and R. M. German, "Effect of powders and binders on material properties and molding parameters in iron and stainless steel powder injection molding process," Powder Technol., vol. 193, no. 2, pp. 162-169, Jul. 2009.

[13] K. H. Kate, R. K. Enneti, S.-J. Park, R. M. German, and S. V. Atre, "Predicting Powder-Polymer Mixture Properties for PIM Design," Crit. Rev. Solid State Mater. Sci., vol. 39, no. 3, pp. 197-214, Mar. 2014.

[14] K. H. Kate, R. K. Enneti, V. P. Onbattuvelli, and S. V. Atre, "Feedstock properties and injection molding simulations of bimodal mixtures of nanoscale and microscale aluminum nitride," Ceram. Int., vol. 39, no. 6, pp. 6887-6897, Aug. 2013.

[15] K. H. Kate, V. P. Onbattuvelli, R. K. Enneti, S. W. Lee, S.-J. Park, and S. V. Atre, "Measurements of Powder-Polymer Mixture Properties and Their Use in Powder Injection Molding Simulations for Aluminum Nitride," JOM, vol. 64, no. 9, pp. 10481058, Sep. 2012.

[16] J. Lenz, R. K. Enneti, V. Onbattuvelli, K. Kate, R. Martin, and S. Atre, "Powder Injection Molding of Ceramic Engine Components for Transportation," JOM, vol. 64, no. 3, pp. 388-392, Mar. 2012.

[17] K. H. Kate, M. Winseck, R. K. Enneti, R. M. German, and S. V. Atre, "Material Property Design in Ceramic Injection Molding," Manuscr. Prep. Int. Mater. Rev., 2015.

[18] K. H. Kate, R. K. Enneti, and S. V. Atre, "Influence of feedstock property measurements and estimates on ceramic injection molding simulations for aluminum nitride," Manuscr. Prep., 2015. 
[19] V. P. Onbattuvelli, R. K. Enneti, S.-J. Park, and S. V. Atre, "The effects of nanoparticle addition on $\mathrm{SiC}$ and AIN powder-polymer mixtures: Packing and flow behavior," Int. J. Refract. Met. Hard Mater., vol. 36, pp. 183-190, Jan. 2013.

[20] V. P. Onbattuvelli, "The effects of nanoparticle addition on the processing, structure and properties of SiC and AIN," 2010.

[21] M. F. Ashby, Materials Selection in Mechanical Design. Butterworth-Heinemann, 2010.

[22] J. R. Groza and A. Zavaliangos, "Sintering activation by external electrical field," Mater. Sci. Eng. A, vol. 287, no. 2, pp. 171-177, Aug. 2000.

[23] K. Biswas, J. Schneider, G. Rixecker, and F. Aldinger, "Comparative bending creep behaviour of silicon carbide sintered with oxynitride additives," Scr. Mater., vol. 53, no. 5, pp. 591-596, Sep. 2005.

[24] J. Gu, Q. Zhang, J. Dang, J. Zhang, and Z. Yang, "Thermal conductivity and mechanical properties of aluminum nitride filled linear low-density polyethylene composites," Polym. Eng. Sci., vol. 49, no. 5, pp. 1030-1034, May 2009.

[25] R. Kochetov, T. Andritsch, U. Lafont, P. H. F. Morshuis, S. J. Picken, and J. J. Smit, "Preparation and dielectric properties of epoxy - BN and epoxy - AIN nanocomposites," in IEEE Electrical Insulation Conference, 2009. EIC 2009, 2009, pp. 397-400.

[26] W. Zhou, "Thermal and dielectric properties of the AIN particles reinforced linear low-density polyethylene composites," Thermochim. Acta, vol. 512, no. 1-2, pp. 183-188, Jan. 2011.

[27] B. L. Zhu, J. Ma, J. Wu, K. C. Yung, and C. S. Xie, "Study on the properties of the epoxy-matrix composites filled with thermally conductive AIN and BN ceramic particles," J. Appl. Polym. Sci., vol. 118, no. 5, pp. 2754-2764, Dec. 2010.

[28] S. H. Risbud, J. R. Groza, and M. J. Kim, "Clean grain boundaries in aluminium nitride ceramics densified without additives by a plasma-activated sintering process," Philos. Mag. Part B, vol. 69, no. 3, pp. 525-533, 1994.

[29] K. A. Khor, K. H. Cheng, L. G. Yu, and F. Boey, "Thermal conductivity and dielectric constant of spark plasma sintered aluminum nitride," Mater. Sci. Eng. A, vol. 347, no. 1-2, pp. 300-305, Apr. 2003. 
[41] W. J. Smothers, 1981 New England Section Topical Meeting on Nonoxide Ceramics: Ceramic Engineering and Science Proceedings, Volume 3, Number 1/2. John Wiley \& Sons, 2009. 


\section{List of Tables}

Table 1. Models used in present study to estimate the feedstock properties

Table 2. Description of symbols used in the paper

Table 3. Molding parameters for AIN tensile bar geometry

Table 4. Density of the AIN feedstock and wax-polymer binder at $300 \mathrm{~K}$

Table 5. Specific heat of the AIN feedstock and wax-polymer binder for temperature between 283 and $423 \mathrm{~K}$

Table 6. Thermal conductivity of AIN feedstock and wax-polymer binder for temperature between 316 and $436 \mathrm{~K}$

Table 7. Viscosity of the AIN feedstock as a function of shear rate between $10^{1}$ and $10^{4}$ $\mathrm{s}^{-1}$ for a temperature range of 415 to $430 \mathrm{~K}$

Table 8. Cross-WLF constants for the AIN feedstock

Table 9. Specific volume of the AIN feedstock as a function of pressure between $0 \mathrm{MPa}$ and $200 \mathrm{MPa}$ for a temperature range of 300 to $450 \mathrm{~K}$

Table 10. Dual-domain Tait constants for the AIN feedstock

Table 11. AIN feedstock property datasets used for injection molding simulations 


\section{List of Figures}

Figure 1. Injection molded AIN tensile bar geometry for (a) experiment \# 1 with 100\% mold fill, (b) experiment \# 2 with $89 \%$ mold fill, (c) experiment \# 3 with $71 \%$ mold fill, and (d) experiment \# 4 with $100 \%$ mold fill

Figure 2. Tensile bar geometry used for injection molding experiments and simulations

Figure 3. Viscosity of AIN feedstock and wax-polymer binder (inset) for a shear rate range of 10 to $10^{4} \mathrm{~s}^{-1}$ and temperatures between 415 and $430 \mathrm{~K}$

Figure 4. Specific volume of AIN feedstock for a temperature range of 300 to $450 \mathrm{~K}$ and pressures between 0 and $200 \mathrm{MPa}$

Figure 5. Progressive mold-filling behavior for simulations performed with dataset 1 at an injection pressure of $38 \mathrm{MPa}$. Progressive fill patterns for (a) $25 \%$ mold fill (b) $50 \%$ mold fill (c) $75 \%$ mold fill, and (d) $100 \%$ mold fill

Figure 6. Onset of short shot for simulations performed with (a) dataset 1 at melt temperature $333 \mathrm{~K}$, (b) dataset 2 at melt temperature of $420 \mathrm{~K}$ and (c) dataset 3 at melt temperature of $333 \mathrm{~K}$

Figure 7. Melt temperature versus percent mold fill for injection molding experiments 14 and simulations

Figure 8. Melt temperature versus part weight for injection molding experiments 1-4 and simulations

Figure 9. Melt temperature versus percent linear shrinkage for injection molding experiments 1-4 and simulations

Figure 10. Melt temperature versus injection pressure for injection molding experiments 1-4 and simulations 

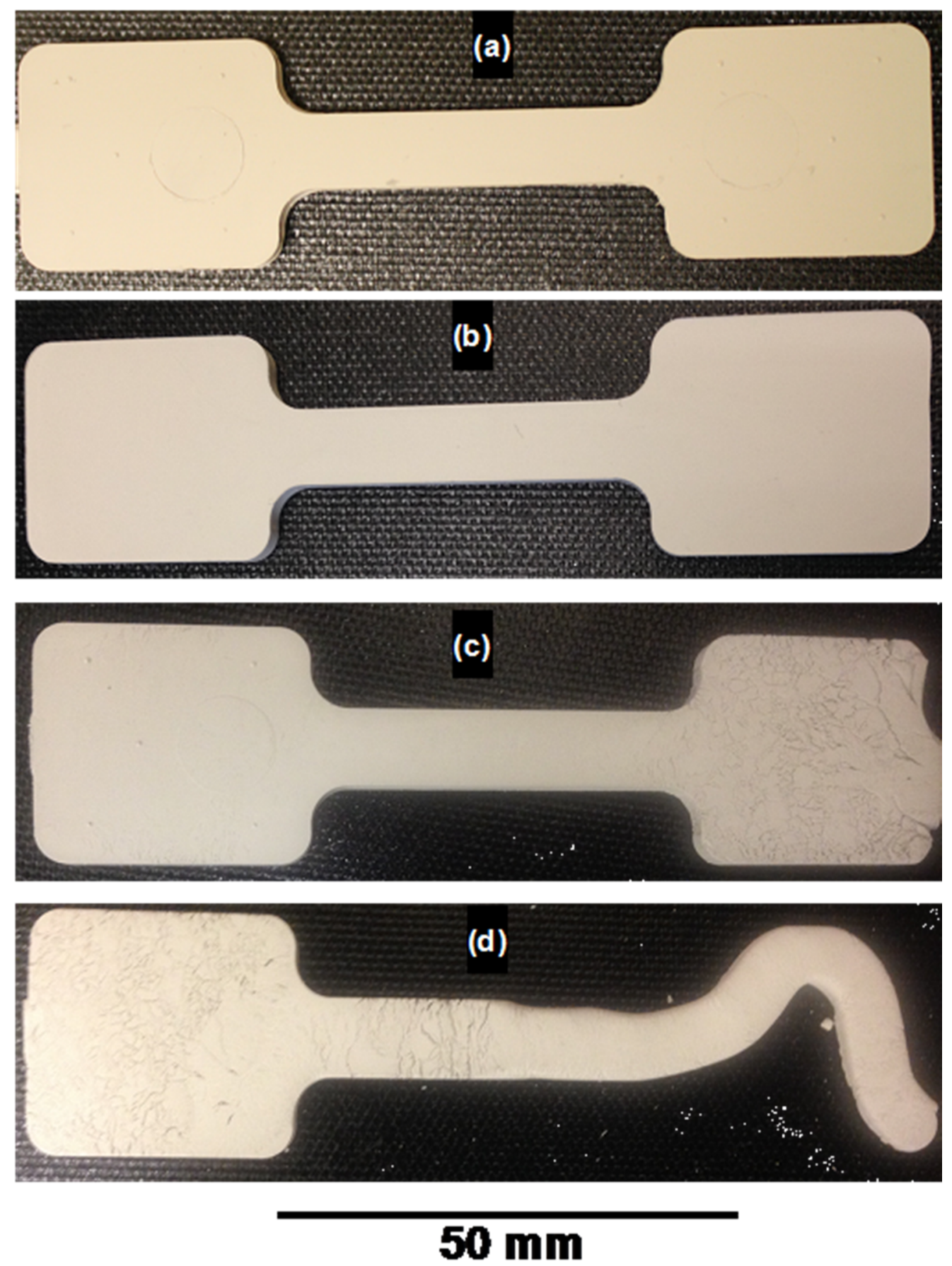

Figure 1. Injection molded AIN tensile bar geometry for (a) experiment \# 1 with 100\% mold fill, (b) experiment \# 4 with 100\% mold fill, (c) experiment \# 2 with $89 \%$ mold fill, and (d) experiment \# 3 with $71 \%$ mold fill. 


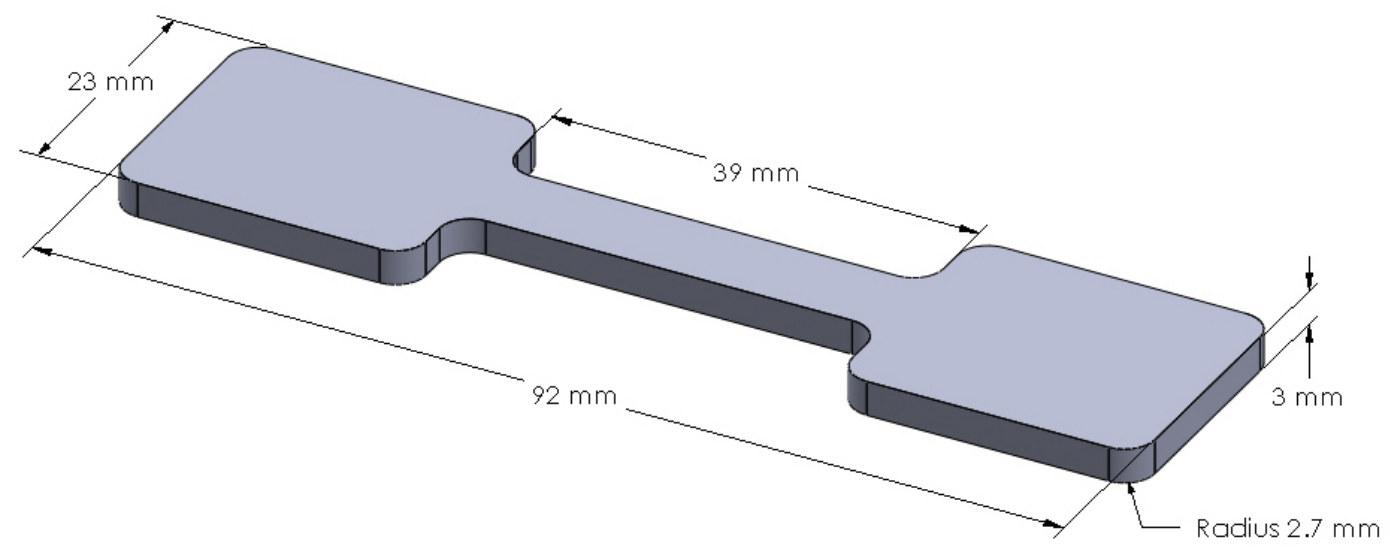

Figure 2. Tensile bar geometry used for injection molding experiments and simulations. 


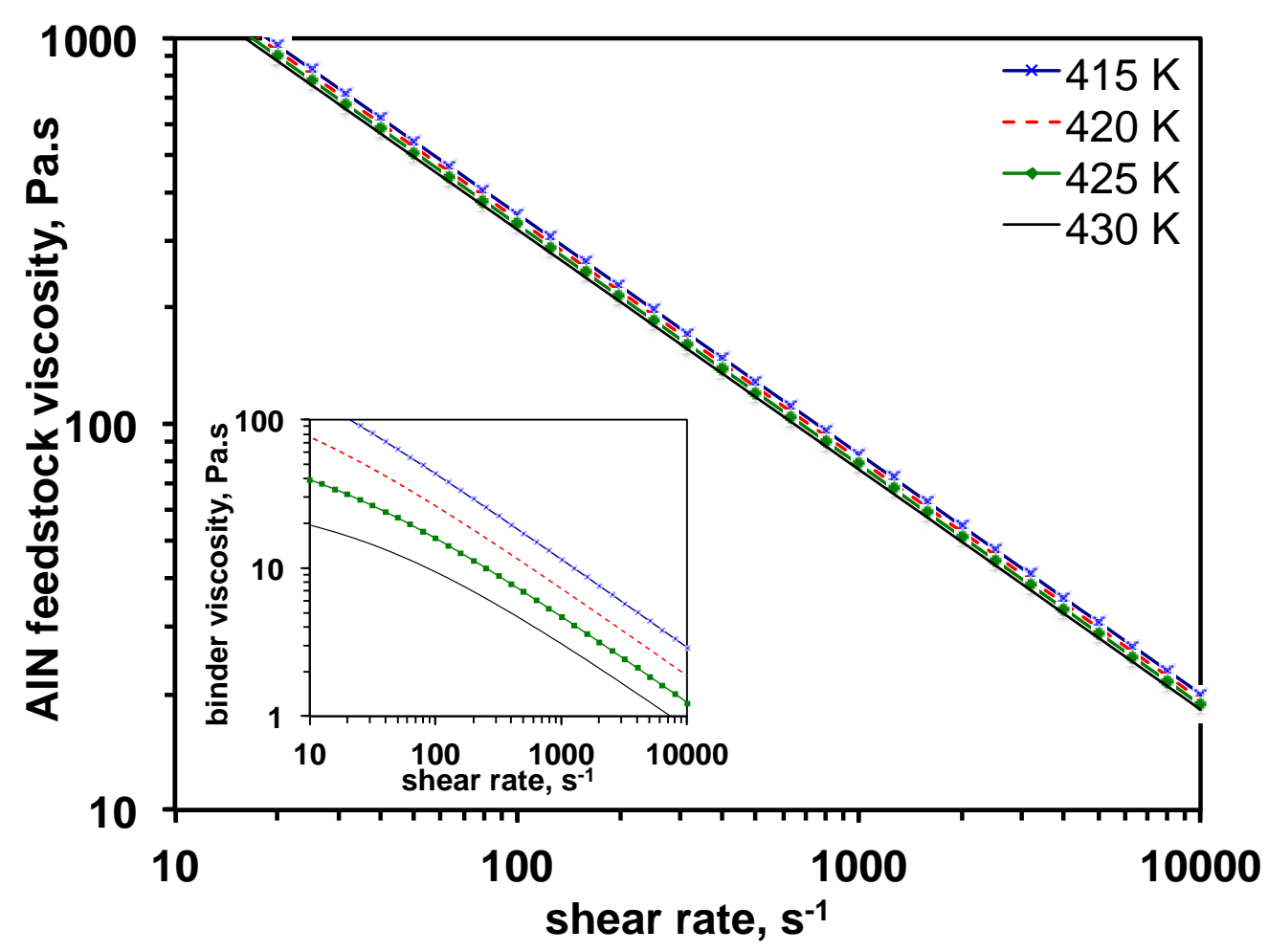

Figure 3. Viscosity of AIN feedstock and wax-polymer binder (inset) for a shear rate range of 10 to $10^{4} \mathrm{~s}^{-1}$ and temperatures between 415 and $430 \mathrm{~K}$. 


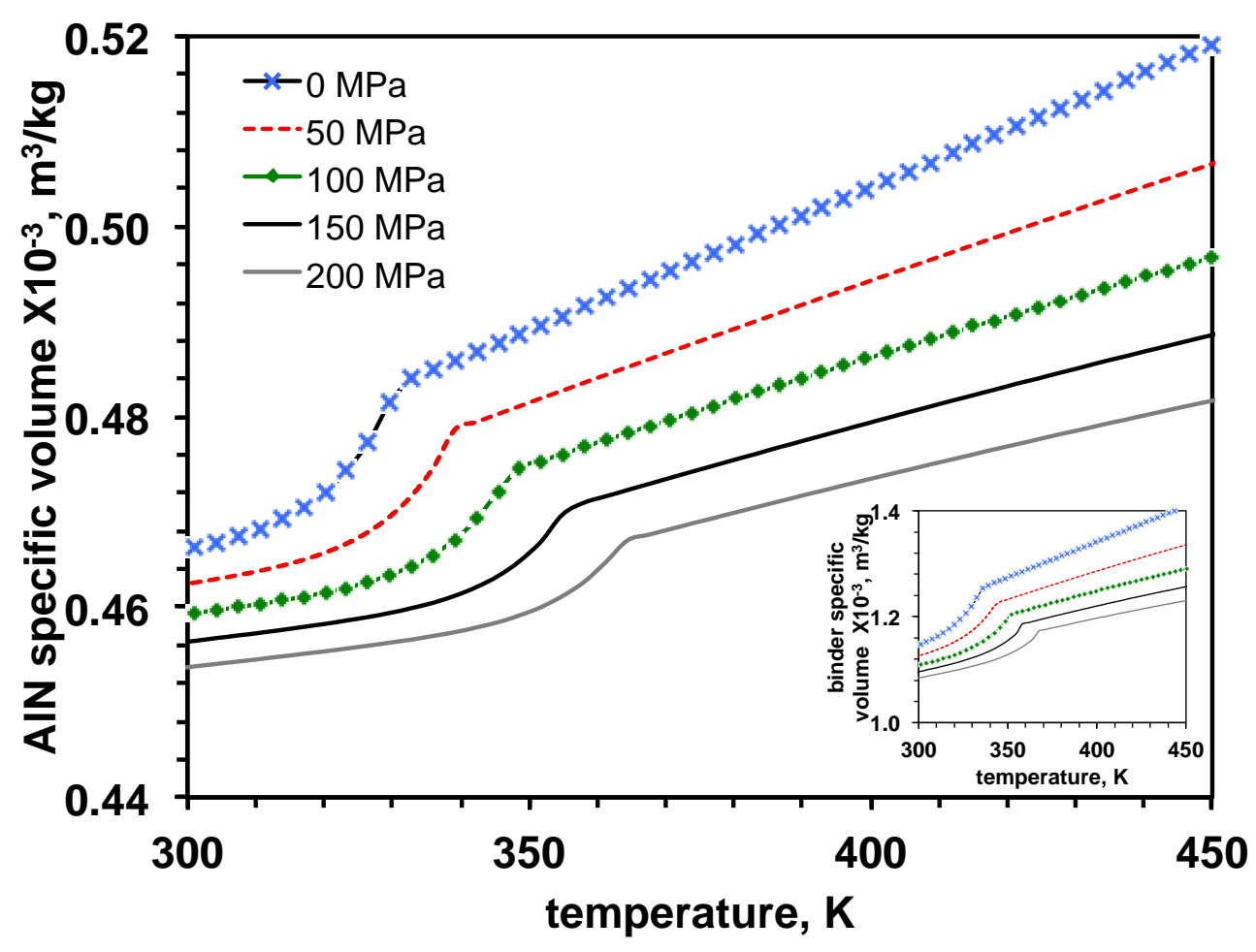

Figure 4. Specific volume of AIN feedstock for a temperature range of 300 to $450 \mathrm{~K}$ and pressures between 0 and $200 \mathrm{MPa}$. 
mold fill, \%

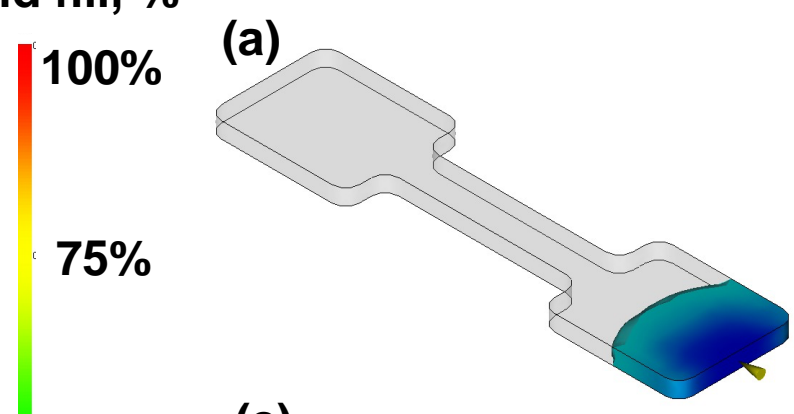

(b)
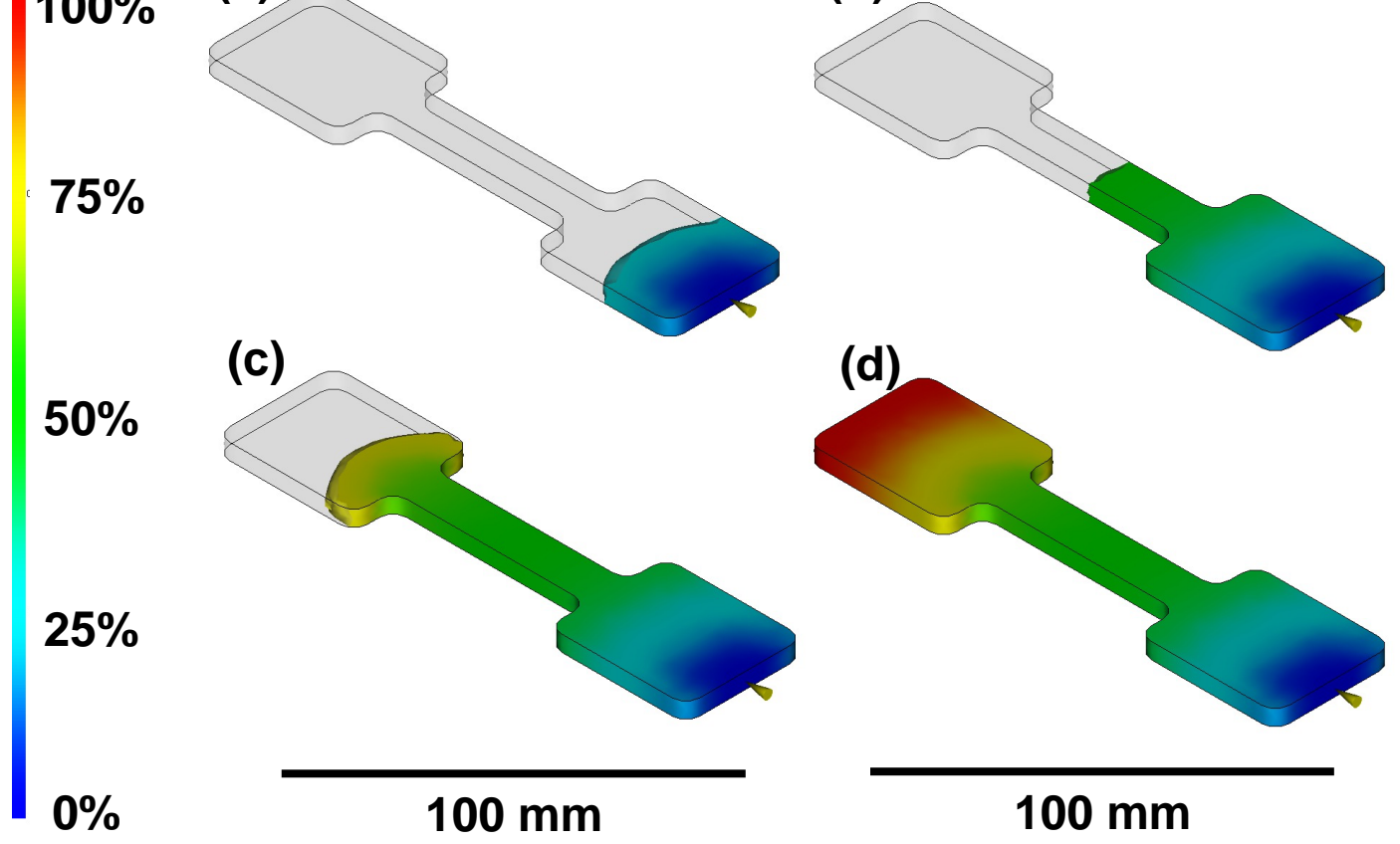

$100 \mathrm{~mm}$

Figure 5. Progressive mold-filling behavior for simulations performed with feedstock property dataset 1 at an injection pressure of 38MPa. Progressive fill patterns for (a) $25 \%$ mold fill (b) $50 \%$ mold fill (c) $75 \%$ mold fill, and (d) $100 \%$ mold fill. 


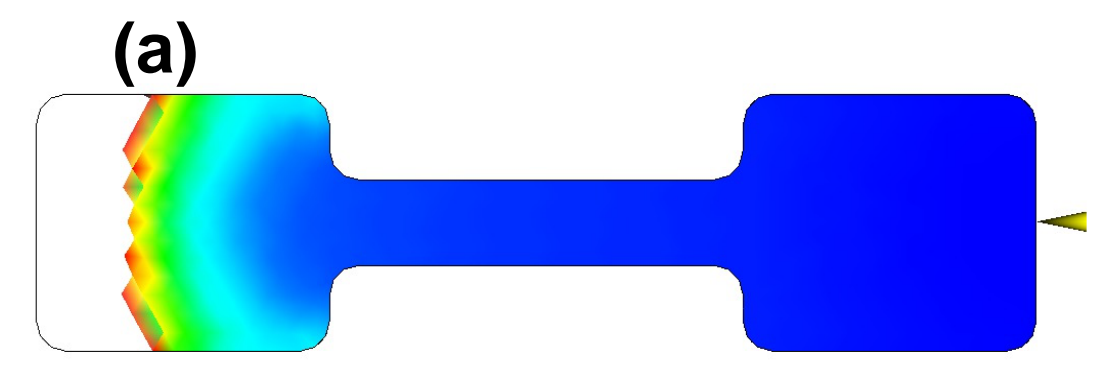

(b)

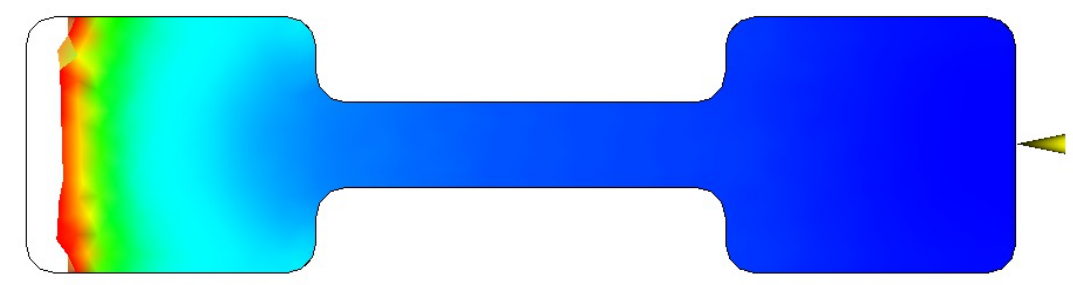

(c)

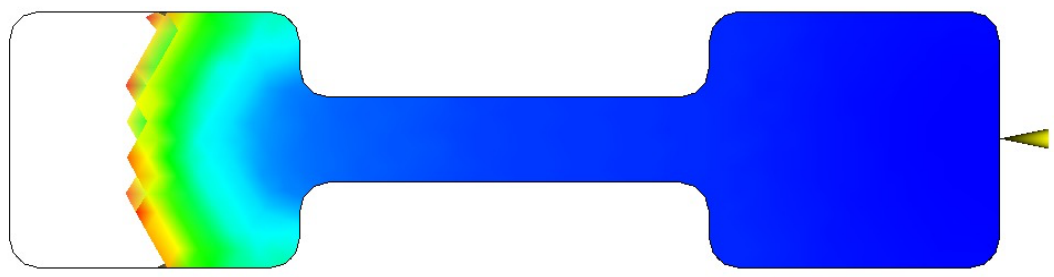

$100 \mathrm{~mm}$

Figure 6. Onset of short shot for simulations performed with (a) feedstock property dataset 1 at melt temperature $333 \mathrm{~K}$, (b) feedstock property dataset 2 at melt temperature of $420 \mathrm{~K}$ and (c) feedstock property dataset 3 at melt temperature of $333 \mathrm{~K}$. 


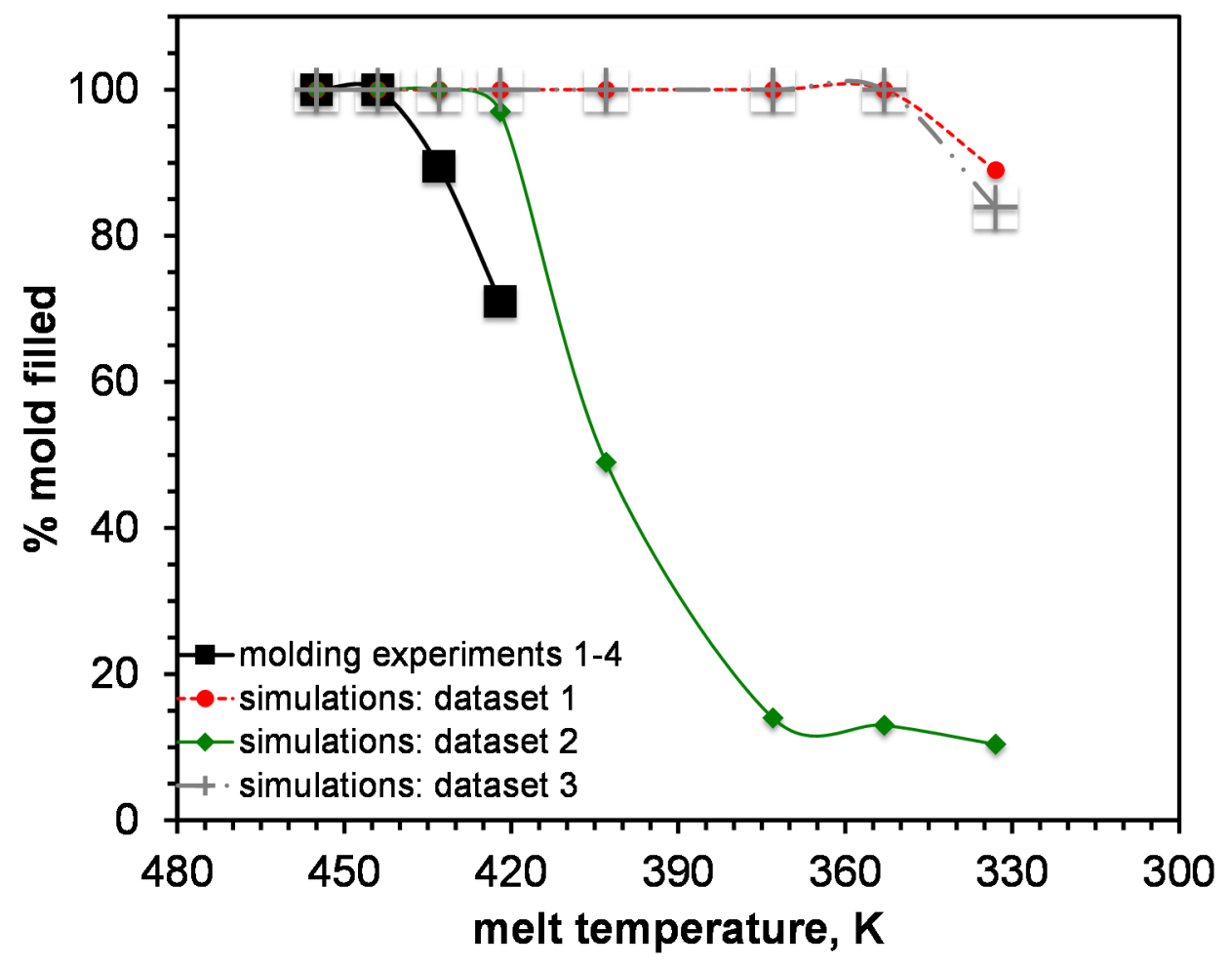

Figure 7. Melt temperature versus percent mold fill for injection molding experiments 14 and simulations. 


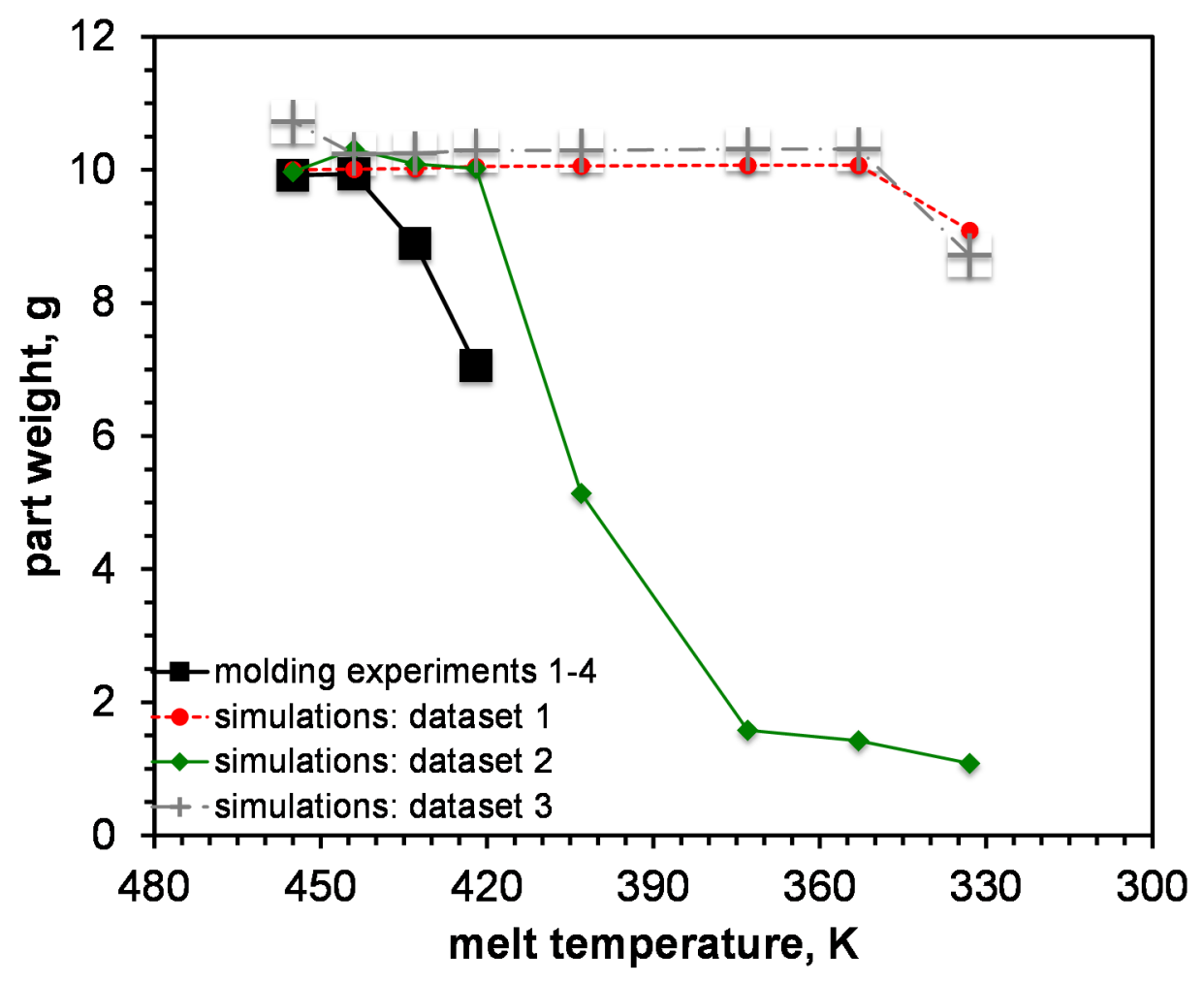

Figure 8. Melt temperature versus part weight for injection molding experiments 1-4 and simulations. 


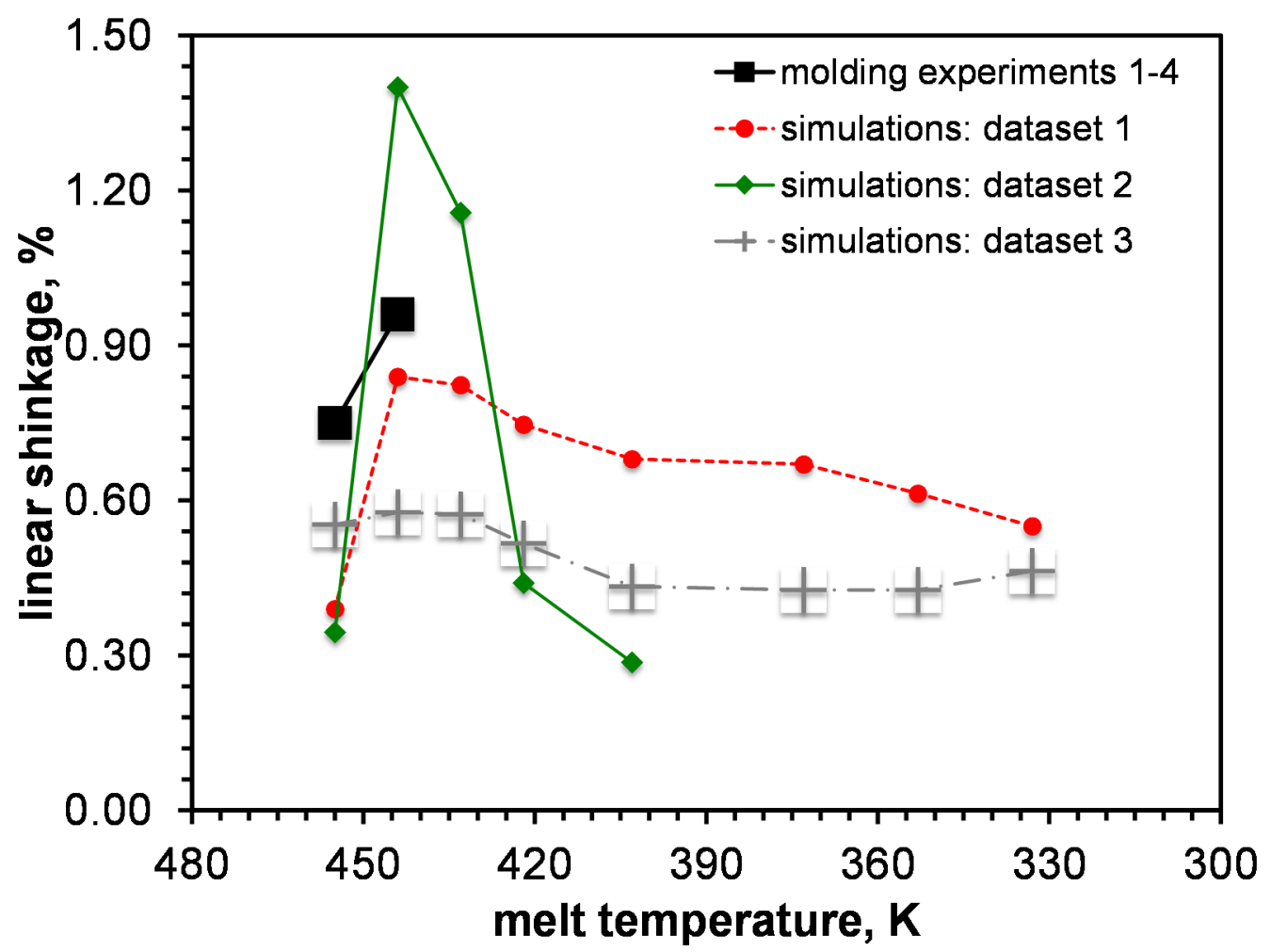

Figure 9. Melt temperature versus percent linear shrinkage for injection molding experiments 1-4 and simulations 


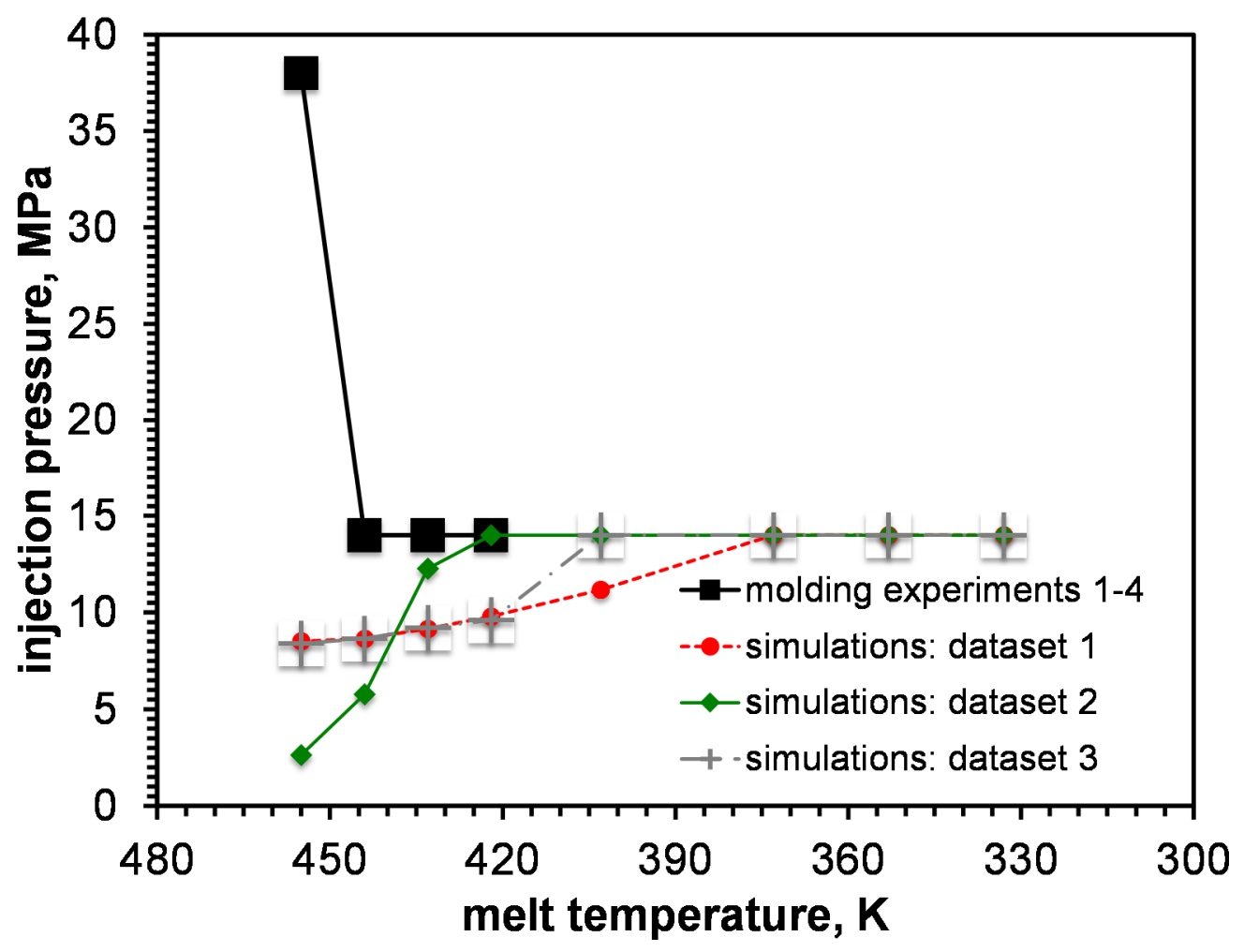

Figure 10. Melt temperature versus injection pressure for injection molding experiments 1-4 and simulations 
Table 1. Models used in present study to estimate the feedstock properties

\begin{tabular}{|c|c|c|}
\hline Property & Empirical relations & \# \\
\hline density & $\frac{1}{\rho_{c}}=\frac{X_{b}}{\rho_{b \exp }}+\frac{X_{p}}{\rho_{p}}$ & 1 \\
\hline \multirow{2}{*}{ volume fraction } & $\phi_{p}=\frac{X_{p} / \rho_{p}}{X_{p} / \rho_{p}+X_{b} / \rho_{b \exp }}$ & 2 \\
\hline & $\phi_{b}=\frac{X_{b} / \rho_{b}}{X_{p} / \rho_{p}+X_{b} / \rho_{b \exp }}$ & 3 \\
\hline specific heat & $C_{p_{c}}=\left[C_{p_{b \text { exp }}} X_{b}+C_{p_{p}} X_{p}\right] *\left[1+A * X_{b} X_{p}\right]$ & 4 \\
\hline thermal conductivity & $1-\phi_{p}=\left(\frac{\lambda_{p}-\lambda_{c}}{\lambda_{p}-\lambda_{\text {bexp }}}\right)\left(\frac{\lambda_{b}}{\lambda_{c}}\right)^{1 / 3}$ & 5 \\
\hline \multirow{3}{*}{ viscosity } & $\eta_{c}=\frac{\eta_{b \exp }}{\left[1-\frac{\phi_{c}}{\phi_{\max }}\right]^{2}}$ & 6 \\
\hline & $\eta_{c}=\frac{\eta_{0}}{1+\left(\frac{\eta_{0} \gamma}{\tau^{*}}\right)^{1-n}}$ & 7 \\
\hline & $\eta_{0}=D_{1} \exp \left[-\frac{A_{1}\left(T-T^{*}\right)}{A_{2}+\left(T-T^{*}\right)}\right]$ & 8 \\
\hline \multirow{5}{*}{ specific volume } & $v_{c}=X_{p} v_{p}+v_{b \exp }\left(1-X_{p}\right)$ & 9 \\
\hline & $v(T, p)=v_{o}(T)\left[1-C \ln \left(1+\frac{p}{B(T)}\right)+v_{t}(T, p)\right]$ & 10 \\
\hline & $\begin{array}{c}\text { for } \mathrm{T}>\mathrm{T}_{\mathrm{t}} \\
v_{o}=b_{1 m}+b_{2 m}\left(T-b_{5}\right) ; \quad B(T)=b_{3 m} e^{\left[-b_{4 m}\left(T-b_{5}\right)\right]} \\
v_{t}(T, p)=0\end{array}$ & 11 \\
\hline & $\begin{array}{c}\text { for } \mathrm{T}<\mathrm{T}_{\mathrm{t}} \\
v_{o}=b_{1 s}+b_{2 s}\left(T-b_{5}\right) ; \quad B(T)=b_{2 s} e^{\left[-b_{4 s}\left(T-b_{5}\right]\right.} \\
v_{t}(T, p)=b_{7} e^{\left[b_{8}\left(T-b_{5}\right)-\left(b_{9} p\right)\right]}\end{array}$ & 12 \\
\hline & $T_{t}(p)=b_{5}+b_{6}(p)$ & 13 \\
\hline
\end{tabular}


Table 2. Description of symbols used in the paper

\begin{tabular}{|c|l|}
\hline Symbol & \multicolumn{1}{|c|}{ Description } \\
\hline$T_{m}$ & melt temperature \\
\hline$X_{c}$ & mass fraction of feedstock \\
\hline$X_{b}$ & mass fraction of binder \\
\hline$X_{p}$ & mass fraction of filler \\
\hline$\rho_{c}$ & density of feedstock \\
\hline$\rho_{b}$ & measured density of binder \\
\hline$\rho_{p}$ & density of filler \\
\hline$\rho_{c e s t}$ & estimated average density of feedstock \\
\hline$C_{p_{c}}$ & specific heat of feedstock \\
\hline$C_{p_{b} \text { exp }}$ & measured specific heat of binder \\
\hline$C_{p_{p}}$ & specific heat of filler \\
\hline$A$ & $=0.2$ fitting constant for spherical powders \\
\hline$C_{p_{c e s t}}$ & estimated average specific heat of feedstock \\
\hline$\lambda_{c}$ & thermal conductivity of feedstock \\
\hline$\lambda_{b \text { exp }}$ & measured thermal conductivity of binder \\
\hline$\lambda_{p}$ & thermal conductivity of filler \\
\hline$\lambda_{c e s t}$ & estimated average thermal conductivity of feedstock \\
\hline$\phi_{c}$ & volume fraction of feedstock \\
\hline$\phi_{b}$ & volume fraction of binder \\
\hline$\phi_{p}$ & volume fraction of filler \\
\hline
\end{tabular}


Table 2 Continued. Description of symbols used in the paper

\begin{tabular}{|c|c|}
\hline symbol & description \\
\hline$\eta_{b \exp }$ & viscosity of binder \\
\hline$\eta_{c}$ & viscosity of feedstock \\
\hline$\phi_{\max }$ & (0.64) volume fraction of critical solids loading of feedstock \\
\hline$\eta_{\text {cest }}$ & estimated average viscosity of feedstock at $\phi_{\max }=0.64$ \\
\hline$\eta_{0}$ & is the zero shear viscosity \\
\hline$\gamma$ & shear rate \\
\hline$\tau^{*}$ & $\begin{array}{l}\text { critical stress level at the transition to shear thinning determined } \\
\text { by curve fitting }\end{array}$ \\
\hline$n$ & power law index in the high shear rate regime \\
\hline$T$ & temperature \\
\hline$T^{*} D_{1}$ and $A_{1}$ & curve fitted coefficients \\
\hline$A_{2}$ & (51.6 K) WLF constant \\
\hline$v_{c}$ & specific volume of feedstock \\
\hline$v_{b \exp }$ & measured specific volume of binder \\
\hline$v_{p}$ & specific volume of filler \\
\hline$\nu_{c e s t}$ & estimated average specific volume of feedstock \\
\hline$v(T p)$ & specific volume at a given temperature and pressure \\
\hline$v_{o}$ & specific volume at zero gauge pressure \\
\hline$p$ & pressure \\
\hline C & $(0.0894)$ constant \\
\hline $\begin{array}{c}b_{1 s} b_{2 s} b_{3 s} b_{4 s} \\
b_{5} b_{7} b_{8} \text { and } b_{9}\end{array}$ & curve-fitted coefficients \\
\hline $\begin{array}{c}b_{1 m} b_{2 m} b_{3 m} \\
b_{4 m} b_{5} \text { and } b_{6}\end{array}$ & curve-fitted coefficients \\
\hline$B(T)$ & pressure sensitivity material as a function of temperature \\
\hline
\end{tabular}


Table 3. Molding parameters for AIN tensile bar geometry

\begin{tabular}{|c|c|c|c|c|}
\hline \multirow{2}{*}{ molding parameters } & \multicolumn{4}{|c|}{ experiment number, \# } \\
\cline { 2 - 5 } & $\# 1$ & $\# 2$ & $\# 3$ & $\# 4$ \\
\hline mold temperature, $\mathrm{K}$ & 297 & 297 & 297 & 297 \\
\hline melt temperature, $\mathrm{K}$ & 455 & 444 & 433 & 422 \\
\hline injection speed, $\mathrm{cm}^{3} / \mathrm{s}$ & 33 & 33 & 33 & 33 \\
\hline injection pressure, MPa & 38 & 14 & 14 & 14 \\
\hline packing pressure 1, MPa for 1 s & 38 & 14 & 14 & 14 \\
\hline packing pressure 2, MPa for 1.2 s & 25 & 9 & 9 & 9 \\
\hline
\end{tabular}

*variation in temperature profile; "variation in pressure profile

Table 4. Density of the AIN feedstock and wax-polymer binder at $300 \mathrm{~K}$

\begin{tabular}{|c|c|c|}
\hline $\begin{array}{c}\text { Density, } \\
\mathrm{m}^{3} / \mathrm{kg}\end{array}$ & $\rho_{c \exp }{ }^{*}$ & $\rho_{c \text { est }}{ }^{+}$ \\
\hline solid & $\mathbf{2 1 5 0}$ & $2130 \pm 20$ \\
\hline melt & $\mathbf{1 9 4 0}$ & $1940 \pm 20$ \\
\hline
\end{tabular}

"measured experimentally; ${ }^{*}$ estimated using Equation 4.1 for 22 data points of $\rho_{p}$

Table 5. Specific heat of the AIN feedstock and wax-polymer binder for temperature between 283 and $423 \mathrm{~K}$

\begin{tabular}{|c|c|c|c|c|c|}
\hline \multirow{2}{*}{$\begin{array}{c}\text { specific heat } C_{p}, \\
\mathrm{~J} / \mathrm{kg}-\mathrm{K}\end{array}$} & \multicolumn{5}{|c|}{ Temperature, $\mathrm{K}$} \\
\cline { 2 - 6 } & $\mathbf{2 8 3}$ & $\mathbf{2 9 8}$ & $\mathbf{3 3 1}$ & $\mathbf{3 7 4}$ & $\mathbf{4 2 3}$ \\
\hline $\mathbf{C}_{\mathbf{p}_{\mathbf{c e x p}}}{ }^{*}$ & $\mathbf{9 2 0}$ & $\mathbf{1 1 1 0}$ & $\mathbf{1 0 9 0}$ & $\mathbf{1 1 3 0}$ & $\mathbf{1 2 1 0}$ \\
\hline $\mathrm{C}_{\mathrm{p}_{\mathrm{c} \text { est }}}{ }^{+}$ & $1050 \pm 35$ & $1240 \pm 35$ & $1570 \pm 35$ & $1850 \pm 35$ & $1150 \pm 35$ \\
\hline
\end{tabular}

"measured experimentally; ${ }^{*}$ estimated using Equation 4.4 for 6 data points of $C_{p_{p}}$ 
Table 6. Thermal conductivity of AIN feedstock and wax-polymer binder for temperature between 316 and $436 \mathrm{~K}$

\begin{tabular}{|c|c|c|c|c|c|}
\hline \multirow{2}{*}{$\begin{array}{c}\text { thermal conductivity, } \\
\text { W/m-K }\end{array}$} & \multicolumn{5}{|c|}{ temperature, $\mathrm{K}$} \\
\cline { 2 - 6 } & $\mathbf{3 1 6}$ & $\mathbf{3 5 6}$ & $\mathbf{3 7 7}$ & $\mathbf{3 9 7}$ & $\mathbf{4 3 6}$ \\
\hline$\lambda_{\boldsymbol{c} \exp ^{*}}$ & $\mathbf{4 . 2 6}$ & $\mathbf{2 . 2 3}$ & $\mathbf{2 . 6 6}$ & $\mathbf{2 . 0 6}$ & $\mathbf{2 . 5 0}$ \\
\hline$\lambda_{c}$ est $^{+}$ & 1.82 & 1.71 & 1.67 & 1.62 & 1.55 \\
& \pm 0.01 & \pm 0.01 & \pm 0.06 & \pm 0.08 & \pm 0.10 \\
\hline
\end{tabular}

"measured experimentally; ${ }^{+}$estimated using Equation 4.5 for 18 data points of $\lambda_{p}$

Table 7. Viscosity of the AIN feedstock as a function of shear rate between $10^{1}$ and $10^{4}$ $\mathrm{S}^{-1}$ for a temperature range of 415 to $430 \mathrm{~K}$

\begin{tabular}{|c|c|c|c|c|c|c|}
\hline \multirow{3}{*}{ shear rate $\mathrm{s}^{-1}$} & \multicolumn{6}{|c|}{ viscosity $\eta_{c}$, Pa.s @ $\phi_{\max }=0.64$} \\
\hline & \multicolumn{2}{|c|}{$\mathrm{T}=415 \mathrm{~K}$} & \multicolumn{2}{|c|}{$T=425 \mathrm{~K}$} & \multicolumn{2}{|c|}{$T=430 \mathrm{~K}$} \\
\hline & $\eta_{c} \exp ^{*}$ & $\eta_{c}$ est $^{+}$ & $\eta_{c} \exp ^{*}$ & $\eta_{c}$ est $^{+}$ & $\eta_{c} \exp ^{*}$ & $\eta_{c}$ est $^{+}$ \\
\hline $10^{1}$ & 1470 & 4830 & 1380 & 1330 & 1340 & 660 \\
\hline $10^{2}$ & 350 & 1460 & 330 & 540 & 320 & 890 \\
\hline $10^{3}$ & 80 & 390 & 80 & 160 & 80 & 100 \\
\hline $10^{4}$ & 20 & 100 & 20 & 40 & 20 & 30 \\
\hline
\end{tabular}

Table 8. Cross-WLF constants for the AIN feedstock

\begin{tabular}{|c|c|c|}
\hline $\begin{array}{c}\text { Cross } \\
\text { WLF } \\
\text { constants }\end{array}$ & $\boldsymbol{\eta}_{\boldsymbol{c}}$ exp $^{*}$ & $\eta_{c}$ est $^{+}$ \\
\hline $\mathrm{n}$ & $\mathbf{0 . 3 8}$ & 0.40 \\
\hline$\tau^{*}, \mathrm{~Pa}$ & $\mathbf{1 8 0}$ & 26860 \\
\hline $\mathrm{D}_{1}, \mathrm{~Pa} . \mathrm{s}$ & $\mathbf{8 . 7 8 \times 1 0 ^ { 1 0 }}$ & $2.23 \times 10^{15}$ \\
\hline $\mathrm{D}_{2}, \mathrm{~K}$ & $\mathbf{2 6 3}$ & 360.93 \\
\hline $\mathrm{A}_{1}, \mathrm{~K} / \mathrm{Pa}$ & $\mathbf{1 4 . 2 4}$ & 49.55 \\
\hline $\mathrm{A}_{2}, \mathrm{~K}$ & $\mathbf{5 1 . 6 0}$ & 51.60 \\
\hline
\end{tabular}

"calculated from Equation 7, 8 and experimental $\left(\eta_{c}\right)$ values from Table 7;

${ }^{+}$calculated from Equation 7, 8 and estimated $\left(\eta_{c}\right)$ values from Table 7 
Table 9. Specific volume of the AIN feedstock as a function of pressure between $0 \mathrm{MPa}$ and $200 \mathrm{MPa}$ for a temperature range of 300 to $450 \mathrm{~K}$

\begin{tabular}{|c|c|c|c|c|c|c|}
\hline \multirow{3}{*}{ Temperature, $\mathrm{K}$} & \multicolumn{6}{|c|}{ specific volume $\times 10^{-3}, \mathrm{~m}^{3} / \mathrm{kg}$} \\
\hline & \multicolumn{2}{|c|}{$\mathrm{P}=0 \mathrm{MPa}$} & \multicolumn{2}{|c|}{$\mathrm{P}=100 \mathrm{MPa}$} & \multicolumn{2}{|c|}{$\mathrm{P}=200 \mathrm{MPa}$} \\
\hline & $\nu_{c} \exp ^{*}$ & $\nu_{c}$ est ${ }^{+}$ & $\nu_{c} \exp ^{*}$ & $\nu_{c}$ est $^{+}$ & $\nu_{c} \exp$ & $\nu_{c}$ est $^{+}$ \\
\hline 300 & 0.47 & 0.48 & 0.46 & 0.47 & 0.45 & 0.46 \\
\hline 350 & 0.49 & 0.50 & 0.48 & 0.49 & 0.46 & 0.47 \\
\hline 400 & 0.50 & 0.51 & 0.49 & 0.50 & 0.47 & 0.49 \\
\hline 450 & 0.52 & 0.53 & 0.50 & 0.50 & 0.48 & 0.49 \\
\hline
\end{tabular}
${ }^{*}$ measured experimentally; ${ }^{+}$estimated using Equation 9

Table 10. Dual-domain Tait constants for the AIN feedstock

\begin{tabular}{|c|c|c|}
\hline $\begin{array}{l}\text { Dual-domain Tait } \\
\text { constants }\end{array}$ & $v_{c} \exp ^{*}$ & $v_{c}$ est $^{+}$ \\
\hline$b_{5}, K$ & 331 & 331 \\
\hline $\mathrm{b}_{6}, \mathrm{~K} / \mathrm{Pa}$ & $1.30 \times 10^{-7}$ & $1.30 \times 10^{-7}$ \\
\hline $\mathrm{b}_{1 \mathrm{~m}, \mathrm{~m}^{3} / \mathrm{kg}}$ & $4.64 \times 10^{-4}$ & $5.77 \times 10^{-4}$ \\
\hline $\mathrm{b}_{2 \mathrm{~m},} \mathrm{~m}^{3} / \mathrm{kg} \cdot \mathrm{K}$ & $1.87 \times 10^{-7}$ & $1.95 \times 10^{-7}$ \\
\hline $\mathrm{b}_{3 \mathrm{~m},} \mathrm{~Pa}$ & $2.05 \times 10^{9}$ & $2.17 \times 10^{9}$ \\
\hline $\mathrm{b}_{4 \mathrm{~m}}, 1 / \mathrm{K}$ & $4.60 \times 10^{-3}$ & $6.15 \times 10^{-3}$ \\
\hline $\mathrm{b}_{1 \mathrm{~s}}, \mathrm{~m}^{3} / \mathrm{kg}$ & $4.55 \times 10^{-4}$ & $5.69 \times 10^{-4}$ \\
\hline $\mathrm{b}_{2 \mathrm{~s},} \mathrm{~m}^{3} / \mathrm{kg} \cdot \mathrm{K}$ & $2.05 \times 10^{-7}$ & $2.05 \times 10^{-7}$ \\
\hline $\mathrm{b}_{3 \mathrm{~s}}, \mathrm{~Pa}$ & $2.52 \times 10^{9}$ & $1.63 \times 10^{9}$ \\
\hline $\mathrm{b}_{4 \mathrm{~s},}, 1 / \mathrm{K}$ & $3.01 \times 10^{-3}$ & $6.35 \times 10^{-3}$ \\
\hline $\mathrm{b}_{7}, \mathrm{~m}^{3} / \mathrm{kg}$ & $5.08 \times 10^{-5}$ & $5.34 \times 10^{-5}$ \\
\hline $\mathrm{b}_{8}, 1 / \mathrm{K}$ & $8.54 \times 10^{-1}$ & $8.97 \times 10^{-1}$ \\
\hline $\mathrm{b}_{9}, 1 / \mathrm{Pa}$ & $5.06 \times 10^{-6}$ & $3.53 \times 10^{-5}$ \\
\hline
\end{tabular}

*calculated from Equation 10-13 and experimental $\left(v_{c}\right)$ values from Table 9; ${ }^{+}$calculated from Equation 1-13 and estimated $\left(v_{c}\right)$ values from Table 9 
Table 11. AIN feedstock property datasets used for injection molding simulations

\begin{tabular}{|c|c|c|c|c|c|}
\hline $\begin{array}{c}\text { AIN feedstock } \\
\text { dataset }\end{array}$ & $\begin{array}{l}\text { density }^{*} \\
\rho_{c}, \mathrm{~kg} / \mathrm{m}^{3}\end{array}$ & $\begin{array}{c}\text { specific } \\
\text { heat }^{* \star} \\
C_{p_{c}}, \mathrm{~J} / \mathrm{kg}-\mathrm{K}\end{array}$ & $\begin{array}{c}\text { thermal } \\
\text { conductivity }^{+} \\
\lambda_{c}, \mathrm{~W} / \mathrm{m}-\mathrm{K}\end{array}$ & $\begin{array}{l}\text { Cross WLF } \\
\text { constants }^{++}\end{array}$ & $\begin{array}{c}\text { Dual- } \\
\text { domain } \\
\text { Tait } \\
\text { constants }^{*}\end{array}$ \\
\hline 1 & $\rho_{c \exp }$ & $C_{p_{c \exp }}$ & $\lambda_{c} \exp$ & $\eta_{c} \exp$ & $\boldsymbol{v}_{c} \exp$ \\
\hline 2 & $\rho_{c \text { est }}$ & $\mathrm{Cp}_{\mathrm{c} \text { est }}$ & $\lambda_{c}$ est & $\eta_{c}$ est & $v_{c}$ est \\
\hline 3 & $\rho_{c \text { est }}$ & $C_{p_{c} \text { est }}$ & $\lambda_{c}$ est & $\eta_{c} \exp$ & $v_{c}$ est \\
\hline
\end{tabular}

*data from Table 4; "data from Table 5; +data from Table 6;

${ }^{++}$data from Table 8; and ${ }^{*+}$ data from Table 10 